Article

\title{
Visible-light-responsive carbon-embedded photocatalyst coupled with plug-flow reactor for decomposition of vaporous aromatics
}

\author{
Ho-Hwan CHUN a, Wan-Kuen JO b,* \\ a Department of Naval Architecture and Ocean Engineering, Pusan National University, 63 Jangjeon-dong, Geumjeong-gu, Busan 609-735, South Korea \\ b Department of Environmental Engineering, Kyungpook National University, 80 University Road, Bukgu, Daegu 702-701, South Korea
}

\section{A R T I C L E I N F O}

\section{Article history:}

Received 19 January 2013

Accepted 19 February 2013

Published 20 June 2013

\section{Keywords:}

Photocatalysis

Vaporous aromatics

Benzene

Toluene

Ethylbenzene

$o$-Xylene

Operational parameter

Continuous treatment

Indoor air control

\begin{abstract}
A B S T R A C T
A plug-flow reactor coated with carbon-doped $\mathrm{TiO}_{2}\left(\mathrm{C}-\mathrm{TiO}_{2}\right)$ powder was investigated for the control of vaporous aromatics (benzene, toluene, ethylbenzene, and $o$-xylene (BTEX)) under a range of experimental conditions. The characteristics of the as-prepared $\mathrm{C}_{-} \mathrm{TiO}_{2}$ and a reference Degussa P25 $\mathrm{TiO}_{2}$ powder were examined using X-ray diffraction, scanning electron microscopy, diffuse-reflectance ultraviolet-visible-near infrared spectroscopy, and Fourier transform infrared spectroscopy. The experimental conditions for the photocatalytic performance of the as-prepared $\mathrm{C}-\mathrm{TiO}_{2}$ photocatalyst were controlled using three operational parameters, relative humidity, flow rate, and input concentration. Unlike other target compounds, very little benzene was removed by the $\mathrm{C}_{-} \mathrm{TiO}_{2}$ photocatalyst under visible-light irradiation. In contrast, the $\mathrm{C}-\mathrm{TiO}_{2}$ exhibited higher removal efficiencies for the other three target compounds (toluene, ethylbenzene, and xylene) compared with those achieved using unmodified $\mathrm{TiO}_{2}$ under visible-light irradiation. The highest removal efficiency was obtained at a relative humidity value of $45 \%$. Specifically, the toluene removal efficiency determined at a relative humidity of $45 \%$ was $78 \%$, whereas it was close to $0 \%$, $7.2 \%$, and $5.5 \%$ for relative humidity values of $20 \%, 70 \%$, and $95 \%$, respectively. In addition, the removal efficiencies for the three target compounds decreased as the flow rate or input concentration increased. These findings indicate that the as-prepared $\mathrm{C}-\mathrm{TiO}_{2}$ photocatalyst could be used for the removal of toxic vaporous aromatics under optimized operating conditions.
\end{abstract}

(C) 2013, Dalian Institute of Chemical Physics, Chinese Academy of Sciences. Published by Elsevier B.V. All rights reserved.

\section{Introduction}

Exposure to toxic pollutants in indoor environments has become an important concern because of the increased amount of time spent in indoor environments. In particular, monocyclic aromatics are highly or potentially toxic to humans [1]. These pollutants have a variety of indoor sources, including cigarette smoke, building materials, furniture, cleaning compounds, dry-cleaning agents, paints, glues, cosmetics, textiles, and com- bustion sources [2,3]. In addition, these compounds are present in urban atmospheres, primarily as a result of human activities, e.g., in motor vehicle exhausts and other combustion processes that use fossil fuels, petroleum storage and distribution, solvent use, and other industrial processes [2]. Once they are in urban air, these compounds can penetrate indoor environments, elevating indoor levels. Accordingly, the development of control strategies is necessary to minimize the health risks to building occupants exposed to high indoor levels of monocyclic aromat-

\footnotetext{
*Corresponding author. Tel: +82-53-950-6584; Fax: +82-53-950-6579; E-mail: wkjo@knu.ac.kr

This work was supported by the National Research Foundation of Korea (NRF) grant funded by the Korean government (MEST) (2011-0027916), the Korea government (MEST) through GCRC-SOP (2011-0030658), and Kyungpook National University Research Fund, 2012.
} 
ics.

Photocatalytic oxidation processes using titanium dioxide $\left(\mathrm{TiO}_{2}\right)$ have been widely used for the oxidation of several environmental pollutants because $\mathrm{TiO}_{2}$ has outstanding photocatalytic activity and stability toward photocorrosion [4-7]. However, treatment using $\mathrm{TiO}_{2}$ requires irradiation with a band-gap energy $\geq 3.2 \mathrm{eV}$, which corresponds to ultraviolet (UV)-light irradiation at a wavelength $\leq 387 \mathrm{~nm}$, to produce electron-hole pairs. The electron-hole pairs then generate superoxide anion radicals and hydroxyl radicals, which can oxidize target chemical species $[8,9]$. Hydroxyl radicals can be detected using photoluminescence techniques [10]. Various techniques for modifying $\mathrm{TiO}_{2}$ have been investigated to enhance light absorption and photocatalytic activities under visible-light irradiation to overcome the need for high band-gap energy. These modifications include nonmetallic doping [11,12], metallic doping $[13,14]$, and dye sensitization $[15,16]$. Among these techniques, modification with nonmetallic carbon (C) has been suggested to be one of the most promising techniques for effectively extending the absorbance of visible light because of its unique electrical and structural properties [12,17]. Moreover, C-modified $\mathrm{TiO}_{2}\left(\mathrm{C}^{-} \mathrm{TiO}_{2}\right)$ reduces the recombination of electron-hole pairs; electron-hole pair recombination reduces the effectiveness of $\mathrm{TiO}_{2}$ as a photocatalyst [17].

Several researchers $[12,18-20]$ have shown that $\mathrm{C}-\mathrm{TiO}_{2}$ photocatalysts prepared using different routes have high photocatalytic activities under visible-light irradiation in the treatment of water pollutants such as methyl orange and methylene blue. In contrast, few studies of air purification using $\mathrm{C}-\mathrm{TiO}_{2}$ photocatalysts are found in the literature, although the photon absorbance kinetics and reaction kinetics of environmental pollutants both differ at liquid-solid and gas-solid interfaces $[21,22]$. This warrants examination of the photocatalytic performance of $\mathrm{C}-\mathrm{TiO}_{2}$ photocatalysts for air pollution applications. A plug-flow reactor can treat greater amounts of air pollutants for a specified time period compared with a batch-type reactor because of its continuous-flow characteristics. Accordingly, this study investigated the use of a plug-flow reactor coated with $\mathrm{C}_{-} \mathrm{TiO}_{2}$ for the control of airborne monocyclic aromatics (benzene, toluene, ethylbenzene, and $o$-xylene (BTEX)) under various experimental conditions. The experimental conditions varied were the relative humidity (RH), flow rate (FR), and input concentration (IC).

\section{Experimental}

\subsection{Experimental protocols}

Figure 1 illustrates the experimental apparatus. The plug-flow photocatalytic reactor was constructed using a Pyrex tube. The inner wall of the Pyrex tube was coated with a thin film of $\mathrm{C}-\mathrm{TiO}_{2}$ photocatalyst or Degussa P25 $\mathrm{TiO}_{2}$, which was used as a reference photocatalyst. A hexahedral tube with light-emitting diode (LED) bulbous lamps was inserted inside the Pyrex tube. The light intensity was measured at a distance from the visible-light lamp equal to the inner surface of the reactor, using a Digital Lux Meter (INS Model DX-100). The

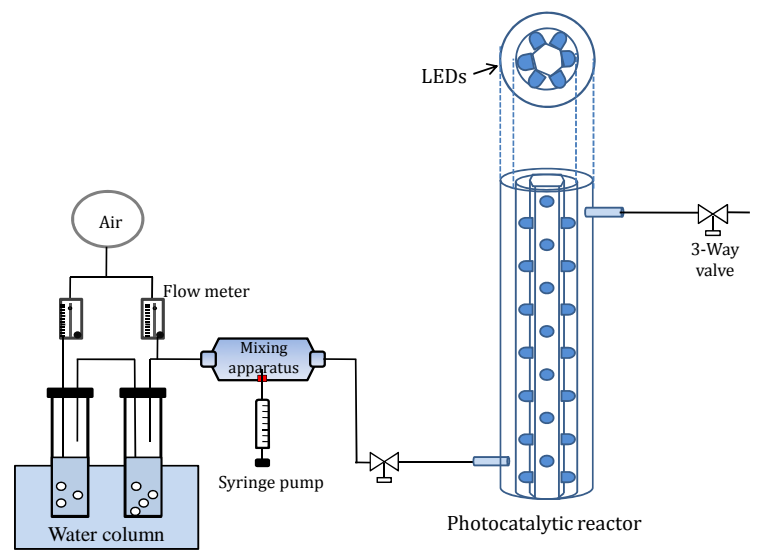

Fig. 1. Schematic diagram of experimental apparatus.

photocatalytic reactor allowed incoming air flow perpendicular to the light sources to enhance distribution of the target compounds on the $\mathrm{C}-\mathrm{TiO}_{2}$ surface. The photocatalytic reactor was blocked with aluminum foil to minimize transmission loss of light from the reactor lamp, as well as to prevent transmission input of light from laboratory light sources. Zero-grade air was supplied from a cylinder and passed through a charcoal filter. This dry air was humidified by passing it through water-containing impingers partially immersed in a water bath (Cole-Parmer HAAKE W26). The RH was measured at the photocatalytic reactor inlet using a humidity meter. The humidified air flowed into a mixing chamber, into which target compounds were simultaneously injected through a syringe pump (KdScientific Model 210). This mixture was then fed into the Pyrex photocatalytic reactor. The BTEX concentrations were adjusted using the stream FRs and injection rates of the target compounds via the syringe pump. The FR was adjusted using flow meters calibrated against a dry-gas meter. After the reactor outlet humidity level reached equilibrium, the reactor was pretreated for $3 \mathrm{~h}$ by flowing humidified air through the photocatalytic reactor. After no contamination with the target compounds was detected in the reactor, the mixture was injected. Both the inlet and outlet concentrations were then measured periodically to check their equality. After the adsorption process between the reactor inner wall and the target compounds reached equilibrium, the reactor lamp was activated.

In the present study, the use of a plug-flow reactor for the control of BTEX was evaluated after coating the reactor with $\mathrm{C}-\mathrm{TiO}_{2}$ powder under various experimental conditions. The experimental conditions were controlled based on the RH, FR, and IC. The RH range for these experiments was 20\%-95\% (20\%, 45\%, 70\%, and 95\%), which covers both dried and humidified environments. The FRs surveyed for this study ranged from 1 to $4 \mathrm{~L} / \mathrm{min}(1,2,3$, and $4 \mathrm{~L} / \mathrm{min})$. The IC was adjusted to 0.1-0.2 ppm, which included an indoor air quality level. To test each parameter, the other parameters were fixed to representative values, which were as follows: $\mathrm{RH}, 45 \%$; FR, $2 \mathrm{~L} / \mathrm{min}$; and IC, $0.1 \mathrm{ppm}$. Visible radiation was supplied by blue LEDs with a peak light intensity of $470 \mathrm{~nm}$. For comparison, this study also examined a plug-flow reactor coated with Degussa P25 $\mathrm{TiO}_{2}$ under the same experimental conditions. 
A thermal oxidation process was used to synthesize the photocatalyst. For the thermal oxidation process, titanium carbide (TiC, Taiji-Ring Ltd., China) powders spread on a Pyrex plate were oxidized at $350{ }^{\circ} \mathrm{C}$ for $8 \mathrm{~h}$, which produced a grey $\mathrm{C}-\mathrm{TiO}_{2}$ powder. For the coatings, the powder $(0.5 \mathrm{~g})$ was ground with $2 \mathrm{ml}$ of $0.1 \mathrm{~mol} / \mathrm{L}$ aqueous ethylenediaminetetraacetic acid solution to produce a viscous paste. The paste was then diluted by slowly adding $10 \mathrm{ml}$ of water, after which $0.1 \mathrm{ml}$ of Triton X-100 were added. After drying this mixture at $100{ }^{\circ} \mathrm{C}$ for $0.5 \mathrm{~h}$, it was coated onto the inner wall of the reactor. Finally, the coated reactor was calcined in an oven at the same temperature as that used for the oxidation for $0.5 \mathrm{~h}$. The characteristics of the as-prepared $\mathrm{C}_{-} \mathrm{TiO}_{2}$ and Degussa $\mathrm{P} 25 \mathrm{TiO}_{2}$ powders were then examined using X-ray diffraction (XRD; Rigaku D/max-2500), scanning electron microscopy (SEM), diffuse-reflectance UV-visible-near-infrared (UV-vis-NIR) spectroscopy (Varian CARY 5G), and Fourier-transform IR (FTIR) spectroscopy (Perkin Elmer Spectrum GX).

\subsection{Sampling and analysis}

Gaseous samples were collected by filling an evacuated 5-L Tedlar bag at a constant FR for 10 min every hour at both the inlet and outlet. Gas from the Tedlar bag was then drawn through a sorbent trap containing $0.3 \mathrm{~g}$ of Tenax TA, using a constant-flow sampling pump (SKC Aircheck Sampler Model 224-PCXR8). All samples were taken at ambient temperature $\left(19-25^{\circ} \mathrm{C}\right)$ and the target compounds collected on the sorbent trap were analyzed by coupling a thermal desorption system (Perkin Elmer ATD 400) with a gas chromatograph (GC; Agilent 7890 A) with a flame ionization detector, using a fused-silica column (Agilent DB-1, $60 \mathrm{~m} \times 0.32 \mathrm{~mm}$ i.d. $\times 1 \mu \mathrm{m}$ film thickness). The peaks of compounds other than the target aromatics on the GC were not high enough to be quantified.

The quality assurance and quality control program for the measurements of gaseous target compounds included laboratory blank traps and spiked samples. At the beginning of the day, a laboratory blank trap was analyzed to check for any trap contamination; however, none was found. An external standard was also analyzed daily to check the quantitative response. When the quantitative response differed from that predicted by the specified calibration equation by more than $10 \%$, a new calibration equation was determined. The method detection limits ranged from 0.7 to $1.2 \mathrm{ppb}$, depending on the target compound.

\section{Results and discussion}

\subsection{Morphological and spectral properties of $\mathrm{C}-\mathrm{TiO}_{2}$ photocatalysts}

The morphological and spectral properties of the as-prepared $\mathrm{C}-\mathrm{TiO}_{2}$ and Degussa $\mathrm{P} 25 \mathrm{TiO}_{2}$ (as a control) were examined using various analytical techniques. As shown in Fig. 2 , the XRD patterns of both photocatalysts exhibited an anatase phase with a major peak at $2 \theta=25.2^{\circ}$, and a rutile phase with a major peak at $2 \theta=27.4^{\circ}$. This XRD pattern is consistent with

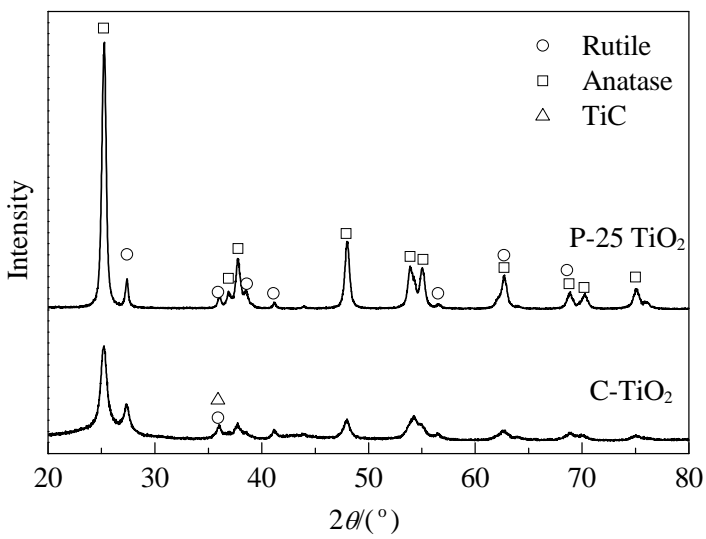

Fig. 2. XRD patterns of $\mathrm{C}-\mathrm{TiO}_{2}$ and Degussa $\mathrm{P} 25 \mathrm{TiO}_{2}$.

that of $\mathrm{C}-\mathrm{TiO}_{2}$ synthesized using a thermal oxidation technique at $350{ }^{\circ} \mathrm{C}$ by Shen et al. [18]. However, in other studies [12,23], it has been reported that $\mathrm{C}-\mathrm{TiO}_{2}$ samples prepared using a hydrothermal or a sol-gel method primarily exhibited an anatase phase. These findings indicate that the spectral properties of $\mathrm{C}-\mathrm{TiO}_{2}$ vary with the synthesis route or conditions. The peak at $2 \theta=36^{\circ}$ for the as-prepared $\mathrm{C}-\mathrm{TiO}_{2}$ is attributed to overlap of the $\mathrm{TiC}$ and $\mathrm{TiO}_{2}$ rutile phases. This assertion is supported by the fact that if this location only reflects the rutile phase, the peak intensity would be lower for $\mathrm{C}-\mathrm{TiO}_{2}$ because the intensities of the other rutile peaks were lower for $\mathrm{C}-\mathrm{TiO}_{2}$ compared with those of unmodified $\mathrm{TiO}_{2}$. However, the peak intensity at $2 \theta=36^{\circ}$ was somewhat higher for $\mathrm{C}-\mathrm{TiO}_{2}$ than for $\mathrm{TiO}_{2}$, suggesting an overlap of the $\mathrm{TiC}$ and $\mathrm{TiO}_{2}$ rutile phases. Consequently, these XRD results probably confirm the presence of both $\mathrm{TiC}$ and $\mathrm{TiO}_{2}$ crystal phases in the as-prepared $\mathrm{C}-\mathrm{TiO}_{2}$.

Figure 3 shows the morphologies of the as-prepared $\mathrm{C}-\mathrm{TiO}_{2}$ and Degussa P25 $\mathrm{TiO}_{2}$. The SEM image shows that both nanocomposites consisted of large amounts of monodispersed particulates. However, the average particle size of the $\mathrm{C}-\mathrm{TiO}_{2}$ agglomerates was larger than that of pure $\mathrm{TiO}_{2}$. This is attributed to an increase in the proportion of the rutile phase formed during the high-temperature oxidation procedure used for the $\mathrm{C}-\mathrm{TiO}_{2}$ preparation because the anatase phase is transformed to the rutile phase, which has a larger particle size, at high temperatures [22]. This assertion was further supported by the XRD results (Fig. 2), in which the peak intensities for the rutile phase were stronger for $\mathrm{C}-\mathrm{TiO}_{2}$ than for $\mathrm{TiO}_{2}$.

The UV-visible absorption spectra of the $\mathrm{C}-\mathrm{TiO}_{2}$ powder and

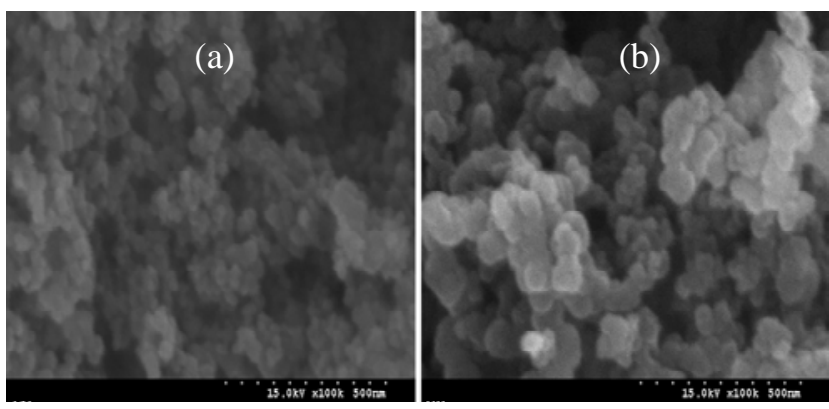

Fig. 3. SEM images of $\mathrm{C}-\mathrm{TiO}_{2}$ (a) and Degussa $\mathrm{P} 25 \mathrm{TiO}_{2}$ (b). 


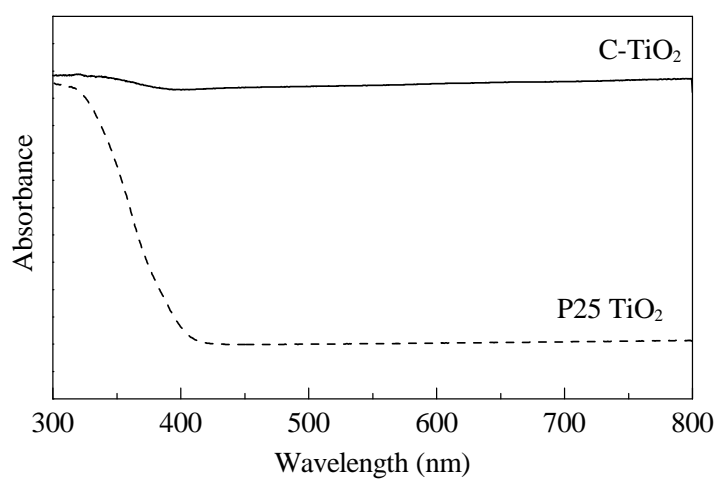

Fig. 4. UV-visible absorption spectra of $\mathrm{C}-\mathrm{TiO}_{2}$ and Degussa $\mathrm{P} 25 \mathrm{TiO}_{2}$.

Degussa $\mathrm{P} 25 \mathrm{TiO}_{2}$ are illustrated in Fig. 4. The $\mathrm{TiO}_{2}$ photocatalyst had an absorption edge at $\lambda \approx 430 \mathrm{~nm}$. Previous studies [24-26] have shown that Degussa P25 $\mathrm{TiO}_{2}$ exhibits an absorption edge at around $430 \mathrm{~nm}$. However, the absorption edge of the $\mathrm{C}-\mathrm{TiO}_{2}$ photocatalyst prepared in the present study shifted well to the visible-light range $(>700 \mathrm{~nm})$. This absorption shift was attributed to the presence of carbonate species at interstitial positions in the $\mathrm{TiO}_{2}$ lattice [27]. These findings further indicate that the as-prepared $\mathrm{C}-\mathrm{TiO}_{2}$ powder could act as an effective photocatalyst under visible-light irradiation.

\subsection{Comparison of $\mathrm{C}-\mathrm{TiO}_{2}$ and Degussa P25 $\mathrm{TiO}_{2}$ for $\mathrm{BTEX}$ removal efficiency}

Figure 5 shows the FTIR spectra of Degussa P25 $\mathrm{TiO}_{2}$ and the $\mathrm{C}-\mathrm{TiO}_{2}$ photocatalyst. The spectra yielded two major peaks at 3429 and $1640 \mathrm{~cm}^{-1}$ for both photocatalysts. The peak at $1640 \mathrm{~cm}^{-1}$ was attributed to $\mathrm{O}-\mathrm{H}$ bending of adsorbed water molecules, and the peak at $3429 \mathrm{~cm}^{-1}$ was ascribed to $\mathrm{O}-\mathrm{H}$ stretching vibrations $[17,28]$. The transmittance intensities for both bands were weaker for $\mathrm{C}-\mathrm{TiO}_{2}$ than for $\mathrm{TiO}_{2}$; this was probably caused by evaporation of water during the $\mathrm{C}-\mathrm{TiO}_{2}$ synthesis, particularly during the thermal oxidation process. In addition, other broad bands below $1000 \mathrm{~cm}^{-1}$ were observed for both the $\mathrm{TiO}_{2}$ and $\mathrm{C}-\mathrm{TiO}_{2}$ powders, although their transmittance intensities differed. These bands appeared to correspond to $\mathrm{TiO}_{2}$ lattice vibrations [28]; however, the transmittance intensities differed between the two photocatalysts. This was

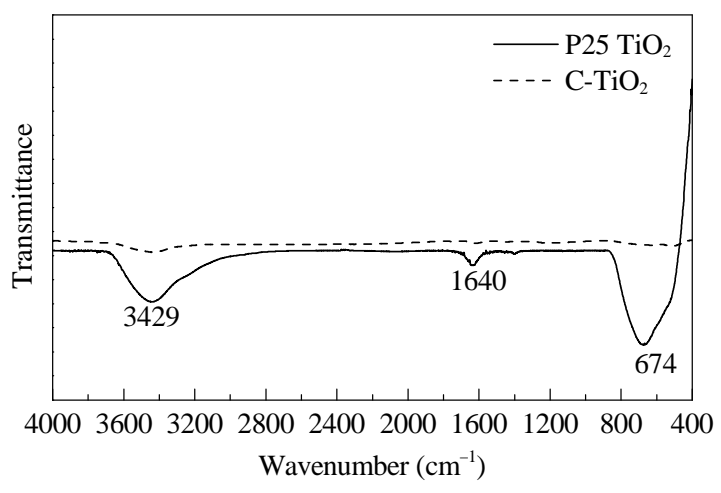

Fig. 5. FTIR spectra of $\mathrm{C}-\mathrm{TiO}_{2}$ and Degussa $\mathrm{P} 25 \mathrm{TiO}_{2}$.

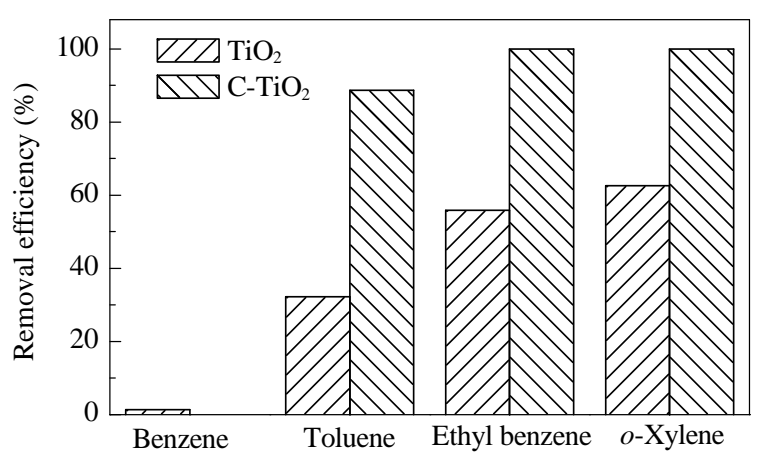

Fig. 6. Comparison of average removal efficiencies with $\mathrm{C}-\mathrm{TiO}_{2}$ and Degussa P25 $\mathrm{TiO}_{2}$.

attributed to lower amounts of $\mathrm{TiO}_{2}$ as a result of coupling with carbon species in $\mathrm{C}-\mathrm{TiO}_{2}$.

The as-prepared $\mathrm{C}-\mathrm{TiO}_{2}$ and Degussa P25 $\mathrm{TiO}_{2}$ were compared for their BTEX removal efficiencies. As shown in Fig. 6, both photocatalysts exhibited a removal efficiency close to zero for benzene. This low benzene removal efficiency was probably the result of a low photocatalytic oxidation rate. Boulamanti et al. [8] reported that among BTEX, benzene had the lowest photocatalytic oxidation rate, $0.147 \mathrm{ppm} /(\mathrm{s} \cdot \mathrm{g})$. In contrast, the C-TiO 2 , with a specific surface area of $213 \mathrm{~m}^{2} / \mathrm{g}$ and a pore volume of $0.7 \mathrm{~cm}^{3} / \mathrm{g}$, showed higher removal efficiencies for the other three target compounds (TEX) compared with those achieved using unmodified $\mathrm{TiO}_{2}$ under visible-light irradiation. This was ascribed to the presence of interstitial carbons in $\mathrm{C}-\mathrm{TiO}_{2}$, which would reduce electron-hole recombination and narrow the energy band-gap of $\mathrm{TiO}_{2}$ by forming a new energy level above the original balance band, thereby enhancing the photocatalytic performance of $\mathrm{TiO}_{2}[12,23]$. The presence of interstitial carbons in $\mathrm{C}^{-\mathrm{TiO}_{2}}$ has been confirmed by X-ray photoelectron spectroscopy results, which were reported in other studies, including another of our studies [29,30]. It is noteworthy that there was an optimum carbon loading on the $\mathrm{TiO}_{2}$ powder for the photocatalytic oxidation of BTEX. In addition, the $\mathrm{C}-\mathrm{TiO}_{2}$ surface probably had larger numbers of active adsorption sites to adsorb TEX molecules because of its larger surface area and pore volume [23]. Furthermore, C-TiO showed higher removal efficiencies for ethylbenzene and $\mathrm{xy}$ lene than for toluene. These findings were attributed to the lower photocatalytic oxidation rate of toluene. According to Boulamanti et al. [8], the photocatalytic oxidation rate for toluene was $0.286 \mathrm{ppm} /(\mathrm{s} \cdot \mathrm{g})$, whereas the rates for ethylbenzene and $p$-xylene were 0.47 and $0.53 \mathrm{ppm} /(\mathrm{s} \cdot \mathrm{g})$, respectively.

\subsection{Effects of RH on BTEX degradation efficiency}

Figure 7 shows the average removal efficiencies for the four target compounds determined over a $3 \mathrm{~h}$ photocatalytic process under four different RH conditions, which cover typical ambient air humidity ranges. The removal efficiencies for benzene were close to zero, regardless of the RH. However, the removal efficiency was highest at an RH of $45 \%$, which is within 


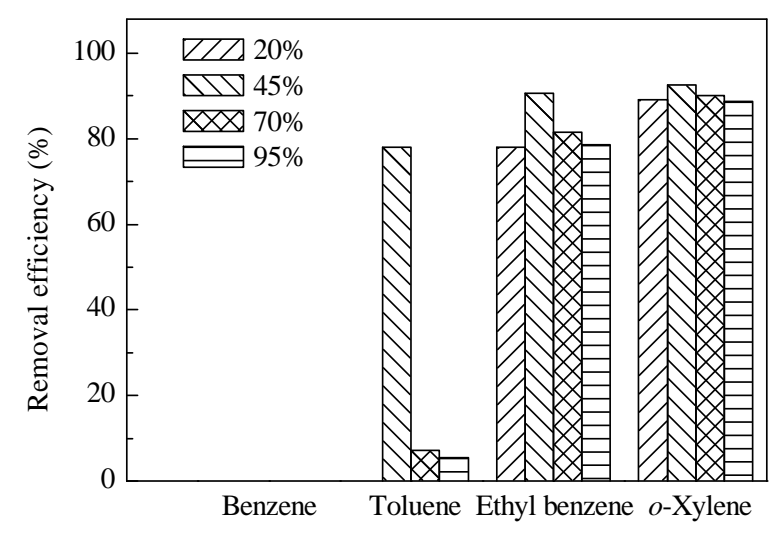

Fig. 7. Average BTEX removal efficiencies in a plug-flow reactor coated with $\mathrm{C}-\mathrm{TiO}_{2}$ under conditions of RHs of $20 \%, 45 \%, 70 \%$, and $95 \%$.

the human comfort range recommended by the American Society of Heating, Refrigerating and Air Conditioning Engineers. Specifically, the toluene removal efficiency determined at an $\mathrm{RH}$ of $45 \%$ was $78 \%$, whereas it was close to $0 \%, 7.2 \%$, and $5.5 \%$ for $\mathrm{RH}$ values of $20 \%, 70 \%$, and $95 \%$, respectively. These results can be attributed to the effects of hydroxyl radical availability on the catalyst surface or competitive adsorption between water and BTEX molecules on the photocatalyst surface [21]. The drop in removal efficiency observed at the low $\mathrm{RH}$ level $(20 \%)$ was ascribed to a decrease in the hydroxyl radical population, which is closely associated with initiating photocatalytic oxidation reactions on the catalyst surface [21]. Moreover, another drop in the removal efficiency was observed at high RH levels (70\% and 95\%), which was probably the result of high adsorption competition by water molecules on the photocatalyst surface. This removal dependence on humidity was inconsistent with the results reported by other researchers, who used other types of photocatalytic units, namely a $\mathrm{TiO}_{2}$-UV lamp [30] or an S-TiO 2 -visible lamp [25]. Ao et al. [31] reported a decreasing trend in gaseous pollutant removal efficiencies with increasing RH. In addition, Jo and Kim [25] reported no RH dependence for certain organic vapor removal efficiencies. Consequently, the dependence of gaseous pollutant removal on RH appears to vary with the type of photocatalyst.

\subsection{Effects of FR on BTEX degradation efficiency}

The FR is another important parameter in plug-flow reactors; it is related to the residence time and face velocity in the reactors. The effects of FR on the BTEX removal efficiencies using the plug-flow reactor were therefore tested. Figure 8 shows the BTEX removal efficiencies determined under four different FRs (1, 2, 3, and $4 \mathrm{~L} / \mathrm{min})$. Similar to the RH effect, the removal efficiencies of benzene were close to zero, regardless of the FR. In contrast, the removal efficiencies for the other target compounds decreased as the FR increased. For example, the removal efficiency of toluene gradually decreased from $89 \%$ to close to zero when the FR increased from 1 to $4 \mathrm{~L} / \mathrm{min}$. The lower TEX degradation efficiency at high FRs may have been caused by insufficient reactor residence time or mass

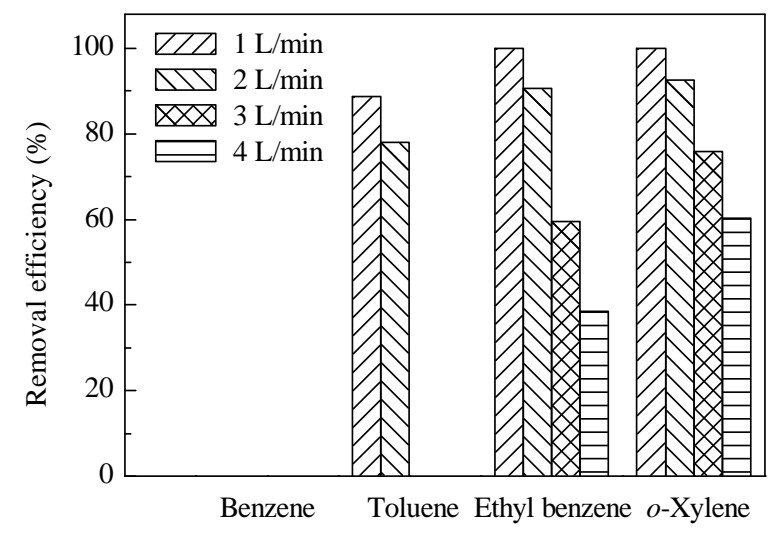

Fig. 8. Average BTEX removal efficiencies in a plug-flow reactor coated with $\mathrm{C}-\mathrm{TiO}_{2}$ under conditions of FRs of $1,2,3$, and $4 \mathrm{~L} / \mathrm{min}$.

transfer as a result of the high FR. The residence times, which were calculated by dividing the reactor volume by the FR, were $22.4,11.2,7.5$, and $5.6 \mathrm{~s}$ for FR values of $1,2,3$, and $4 \mathrm{~L} / \mathrm{min}$, respectively. In addition, the bulk mass transport of the target hydrocarbons from the gas phase to the solid surface of the photocatalyst particles might be reduced as a result of decreased convection and diffusion effects in response to increasing face velocity [31]. This would result in a decrease in the photocatalytic removal efficiencies for the target compounds at high FR values. These results confirmed that the FR is an important parameter in the application of as-prepared $\mathrm{C}-\mathrm{TiO}_{2}$ photocatalytic technology to the purification of vaporous BTEX.

\subsection{Effects of ICs on BTEX degradation efficiency}

The BTEX removal efficiencies determined at three different IC conditions $(0.1,0.5$, and $1.0 \mathrm{ppm})$, which cover indoor air concentrations, are presented in Fig. 9. Similar to the RH and FR effects, the removal efficiencies for benzene were close to zero, regardless of the IC. However, the removal efficiencies of the other target compounds decreased as the IC levels increased. For example, the removal efficiency of xylene gradually decreased from $93 \%$ to $6 \%$ when the IC increased from 0.1 to $1.0 \mathrm{ppm}$. This IC dependence was ascribed to the competition of pollutant molecules for active adsorption sites on the

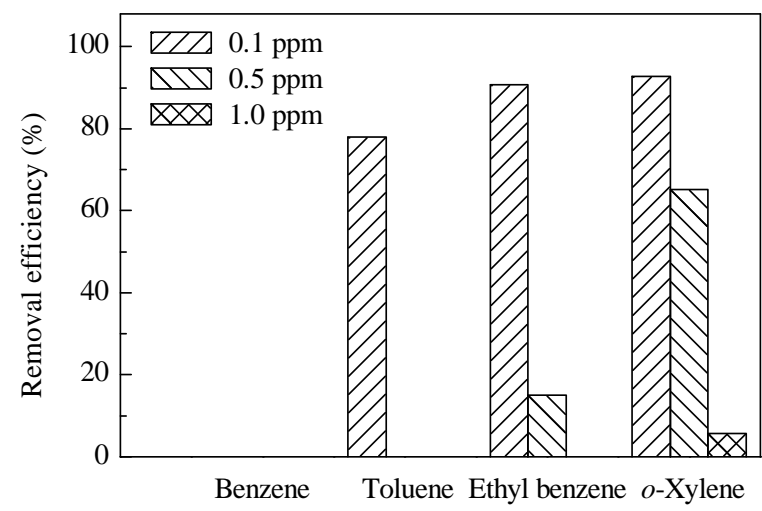

Fig. 9. Average BTEX removal efficiencies in a plug-flow reactor coated with $\mathrm{C}-\mathrm{TiO}_{2}$ under conditions of ICs of $0.1,0.5$, and $1.0 \mathrm{ppm}$. 


\section{Graphical Abstract}

Chin. J. Catal., 2013, 34: 1256-1261 doi: 10.1016/S1872-2067(12)60549-X

Visible-light-responsive carbon-embedded photocatalyst coupled with plug-flow reactor for decomposition of vaporous aromatics

Ho-Hwan CHUN, Wan-Kuen JO*

Pusan National University, South Korea;

Kyungpook National University, South Korea

A plug-flow reactor coated with carbon-doped $\mathrm{TiO}_{2}\left(\mathrm{C}-\mathrm{TiO}_{2}\right)$ powder was investigated for the control of vaporous aromatics (benzene, toluene, ethylbenzene, and $o$-xylene) under a range of experimental conditions.

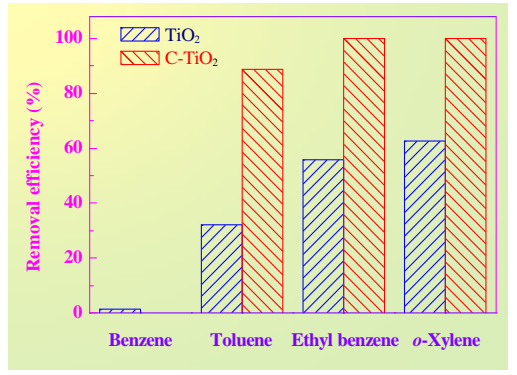

C- $\mathrm{TiO}_{2}$ surface because the adsorption of pollutants on the photocatalyst surface is a significant operational factor in photocatalytic processes [32,33]. Moreover, the competition for adsorption sites would be greater under high IC conditions. In contrast, Noguchi et al. [34] reported that the photocatalytic efficiencies increased with increasing IC for aldehyde species from 30 to 2000 ppm under a UV-light intensity of $1.0 \mathrm{~mW} / \mathrm{cm}^{2}$ and an RH of $40 \%$. Accordingly, different photocatalytic conditions would cause different IC dependences of the gaseous pollutant removal efficiencies.

\section{Conclusions}

This study was conducted to examine a plug-flow reactor coated with $\mathrm{C}-\mathrm{TiO}_{2}$ powders for the control of gaseous aromatic hydrocarbons under a range of experimental conditions. The morphological and spectral properties of the as-prepared $\mathrm{C}-\mathrm{TiO}_{2}$ were determined using various analytical techniques. The as-prepared $\mathrm{C}-\mathrm{TiO}_{2}$ photocatalysts could be used for the removal of toxic gaseous aromatic hydrocarbons when the operating conditions were optimized. The major operating conditions were determined on the basis of the RH, FR, and IC. The enhanced performance of the as-prepared $\mathrm{C}_{-} \mathrm{TiO}_{2}$ photocatalysts for gaseous pollutant removal was demonstrated by the finding that $\mathrm{C}-\mathrm{TiO}_{2}$ exhibited higher removal efficiencies for three target compounds (TEX) than those achieved using unmodified $\mathrm{TiO}_{2}$ under visible-light irradiation. However, unlike the other target compounds, very little benzene was removed using the photocatalytic unit constructed in this study.

\section{References}

[1] Chen C S, Hseu Y C, Liang S H, Kuo J-Y, Chen S C. J Hazard Mater, 2008, 153: 351

[2] Ohura T, Amagai T, Shen X, Li S, Zhang P, Zhu L. Atmos Environ, 2009, 43: 6352

[3] Schlink U, Thiem A, Kohajda T, Richter M, Strebel K. Sci Total Environ, 2010, 408: 3840

[4] Suriyawong A, Smallwood M, Li Y, Zhuang Y, Biswas P. Aeros Air Qual Res, 2009, 9: 394

[5] Xiang Q J, Yu J G. Chin J Catal (催化学报), 2011, 32: 525

[6] Wu Q, Wu Zh J, Li Y L, Gao H T, Pu L Y, Zhang T H, Du L X. Chin J
Catal (催化学报), 2012, 33: 1743

[7] Zhang J, Yan S, Fu L, Wang F, Yuan M Q, Luo G X, Xu Q, Wang X, Li C. Chin J Catal (催化学报), 2011, 32: 983

[8] Boulamanti A K, Korologos C A, Philippopoulos C J. Atmos Environ, 2008, 42: 7844

[9] Rajeshwara K, Osugi M E, Chanmanee W, Chenthamarakshan C R, Zanoni M V B, Kajitvichyanukul P, Krishnan-Ayer R. J Photochem Photobiol C, 2008, 9: 171

[10] Xiang Q J, Yu J G, Wong P K. J Colloid Interface Sci, 2011, 357: 163

[11] Chen L J, Wang T, Chen F, Zhang J L. Chin J Catal (催化学报), 2011, 32: 699

[12] Li H Y, Wang D J, Fan H M, Wang P, Jiang T F, Xie T F. J Colloid Interface Sci, 2011, 354: 175

[13] Bouras P, Stathatos E, Lianos P. Appl Catal B, 2007, 73: 51

[14] Yang X, Xu L L, Yu X D, Guo Y H. Catal Commun, 2008, 9: 1224

[15] Ozcan O, Yukruk F, Akkaya E U, Uner D. Appl Catal B, 2007, 71: 291

[16] Vinu R, Polisetti S, Madras G. Chem Eng J, 2010, 165: 784

[17] Janus M, Inagaki M, Tryba B, Toyoda M, Morawski A W. Appl Catal $B, 2006,63: 272$

[18] Shen M, Wu Z Y, Huang H, Du Y K, Zou Z G, Yang P. Mater Lett, 2006, 60: 693

[19] Ren W J, Ai Z H, Jia F L, Zhang L Z, Fan X X, Zou Z G. Appl Catal B, 2007, 69: 138

[20] Park Y, Kim W, Park H, Tachikawa T, Majima T, Choi W. Appl Catal $B, 2009,91: 355$

[21] Demeestere K, Dewulf J, Van Langenhove H. Crit Rev Environ Sci Technol, 2007, 37: 489

[22] Fujishima A, Zhang X, Tryk D A. Surf Sci Rep, 2008, 63: 515

[23] Lin X X, Rong F, Ji X, Fu D G. Microporous Mesoporous Mater, 2011, 142: 276

[24] Znad H, Kawase Y.J Mol Catal A, 2009, 314: 55

[25] Jo W K, Kim J T. J Chem Technol Biotechnol, 2010, 85: 485

[26] Veréb G, Ambrus Z, Pap Z, Kmetykó Á, Dombi A, Danciu V, Cheesman A, Mogyorósi K. Appl Catal A, 2012, 417-418: 26

[27] Wong M-S, Hsu S-W, Rao K K, Kumar C P.J Mol Catal A, 2008, 279: 20

[28] Wei F Y, Ni L S, Cui P.J Hazard Mater, 2008, 156: 135

[29] Liu S W, Li C, Yu J G, Xiang Q J. CrystEngComm, 2011, 13: 2533

[30] Yu J G, Dai G P, Xiang Q J, Jaroniec M. J Mater Chem, 2011, 21: 1049

[31] Ao C H, Lee S C, Mak C L, Chan L Y. Appl Catal B, 2003, 42: 119

[32] Van Gerven T, Mul G, Moulijn J, Stankiewicz A. Chem Eng Prog, 2007, 46: 781

[33] Yang R, Zhang Y P, Xu Q J, Mo J H. Atmos Environ, 2007, 41: 1221

[34] Noguchi T, Fujishima A, Sawunytama P, Hashimoto K. Environ Sci Technol, 1998, 32: 3831 